\title{
Commentary: CABG vs PCI in NSTEMI/UA: Abbreviated alternatives
}

\author{
Zaid M. Abdelsattar, MD, MS, and Juan A. Crestanello, MD
}

From the Department of Cardiovascular Surgery, Mayo Clinic, Rochester, Minn.

Disclosures: Authors have nothing to disclose with regard to commercial support.

Received for publication Aug 29, 2019; revisions received Aug 29, 2019; accepted for publication Aug 30, 2019; available ahead of print Sept 23, 2019.

Address for reprints: Juan A. Crestanello, MD, Department of Cardiovascular Surgery, Mayo Clinic, 200 First St SW Rochester, MN 55905 (E-mail: crestanello.juan@mayo.edu).

J Thorac Cardiovasc Surg 2020;160:936

$0022-5223 / \$ 36.00$

Copyright (c) 2019 by The American Association for Thoracic Surgery

https://doi.org/10.1016/j.jtcvs.2019.08.133

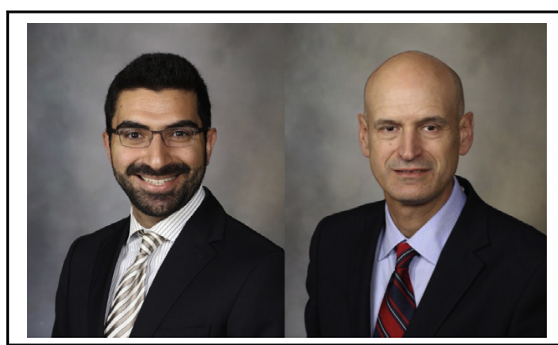

Zaid M. Abdelsattar, MD, MS (leff), and Juan A. Crestanello, MD (right)

Central Message

CABG and PCI are alternatives for the management of NSTEMI/UA. Optimal patient management should include a discussion within a heart team.

See Article page 926. score matching, the authors demonstrate excellent longterm outcomes after coronary artery bypass grafting $(\mathrm{CABG})$ and note a survival advantage in male patients.

While the study adds to the literature on the fact that either percutaneous coronary intervention (PCI) or CABG are appropriate for the right patient, it does not specify who that patient is who is best served by either approach. Determining the individualized approach to the patient with non-ST-segment elevation myocardial infarction/unstable angina, based on their anatomy and risk profile, ideally stems from a multidisciplinary discussion within a designated heart team. This further highlights an understated key finding in the paper. In this study, the absence of an on-site cardiac surgery unit (ie, a heart team) was associated with worse outcomes. In the present study, 16 of 25 hospitals $(64 \%)$ did not have a heart team evaluate the patient for their optimal revascularization strategy, and presumably those patients went down the PCI pathway. Furthermore, the exact revascularization strategy (beyond PCI or CABG) is not elucidated, particularly in the long

study period of 16 years, and there is still a myriad of unmeasured confounders that are not accounted for, despite their rigorous efforts at propensity matching.

The authors are commended on their important work in what they call a "real-world" practice. The readership is reminded that there are plenty of discussions to be had beyond the abbreviations of PCI versus CABG for patients with non-ST-segment elevation myocardial infarction/unstable angina in the "real world."

\section{Reference}

1. Ram E, Sternik L, Klempfner R, Iakobishvili Z, Peled Y, Shlomo N, et al Outcomes of different revascularization strategies among patients presenting with acute coronary syndromes without ST elevation. J Thorac Cardiovasc Surg. 2020;160:926-35.e6. 